\title{
Application of Plasmid Analysis to Infection Control
}

One by-product of the explosion of technologies related to recombinant DNA has been the development of simple and rapid techniques for isolating plasmid DNA., ${ }^{1,2}$ This technology has been applied to answer questions in two major areas of nosocomial infection control. One application has been to questions related to the development of antimicrobial resistance by common nosocomial pathogens. The second major application has been to serve as a strain marker in epidemiologic investigation. Both applications have mainly been on a research basis, but in selected circumstances can provide practical information to guide infection control practice.

Hospitals present an unusual environment where resistance to antimicrobials in bacterial pathogens is encountered commonly. These bacteria become resistant either by mutation or by the acquisition of new DNA. The new DNA is most often acquired through R-plasmid exchange and this mechanism appears responsible for most of the clinically significant resistance encountered. Two important exceptions to this are intrinsic beta-lactam or "methicillin" resistance in Staphylococcus aureus and Staphylococcus epidermidis along with Type 1 beta-lactamase production by gram-negative pathogens such as Entero-

From the Department of Internal Medicine, The University of Michigan Medical Center, Ann Arbor, Michigan.

Address reprint requests to Dennis $R$. Schaberg, MD, Department of Internal Medicine, Office of the Chairman, The University of Michigan Medical Center, 3100A Taubman Center, Ann Arbor, MI 48109-0368. bacter cloacae or Pseudomonas aeruginosa. These resistances are chromosomally mediated, and thus, R-plasmid analysis has not been able to shed much light on these problems. Resistance to other antimicrobics, in particular the aminoglycosides and beta-lactams, is often due to R-plasmids, and study of these elements has improved our understanding of their contribution to the development of resistance.

Within the hospital environment, three levels of genetic organization play roles in antimicrobial resistance due to R-plasmids. These are spread of R-plasmid containing strains, R-plasmid spread from strain to strain, and the process of transposition of a resistance gene onto R-plasmids with subsequent spread via strain dissemination or R-plasmid transfer into different strains. Transposition and other more classic recombination events probably play important roles in "stacking" new resistance onto preexisting R-plasmids. This is often a matter only for speculation. However, in support of this are the studies of Rubens and co-workers. ${ }^{3}$ They found that during a prolonged outbreak of nosocomial infections which were resistant to gentamicin, transposition played a role. The problem began with infection due to Serratia marcescens which contained a large conjugative R-plasmid lacking the gentamicin-resistance determinant and a smaller, nonconjugative plasmid where the gentamicin resistance was located. The gentamicin resistance was on a transposition element which made its way onto the large selftransferable plasmid. This R-plasmid along with gentamicin resistance subsequently was found in Klebsiella 
pneumoniae as well as several other genera. Transposition with subsequent R-plasmid dissemination thus helped explain the gentamicin resistance which was encountered.

The role of R-plasmid transfer in other outbreaks has been documented as well. Tompkins described the spread of an identical R-plasmid among different genera in a single hospital accounting for most of the resistance to gentamicin seen during that time. ${ }^{4}$ In the report in this issue, Shlaes ${ }^{5}$ adds evidence that even in the absence of an outbreak, this same process operates. In outbreak settings, we usually are able only to speculate about the development of resistance. The prospective nature of the investigation by Shlaes in a non-outbreak setting documents the spread of R-plasmids among genera in ICU settings. The spread of specific plasmids among five species of Enterobacteriaceae during the 6 months of study points to the dynamic nature of gene exchange occurring constantly within the hospital. Just where this gene exchange is taking place within the ICU is not known, unfortunately, and thus control remains directed at preventing strain dissemination. Barrier precautions applied to patients colonized or infected with antimicrobial resistant strains of Enterobacteriaceae are one strategy which has helped prevent the spread of resistance in similar settings. ${ }^{6}$

Prevention of spread of organisms within the hospital often depends on identification of the reservoir and mode of transmission of the infecting strain. In some circumstances, it is necessary to type common pathogens in order to be certain of strain identity. Agarose gel electrophoresis of total plasmid DNA content has provided one method to type individual strains lending evidence of strain identity. This technique is most useful for isolates where readily available typing systems are lacking such as S. epidermidis popularized by Archer et al ${ }^{7,8}$ or Serratia marcescens where it was used by John and co-workers to assist in investigation. ${ }^{9}$ It has also been used where traditional typing failed, exemplified by the studies of McGowan, ${ }^{10}$ who found $70 \%$ of $S$. aureus isolates from a high-risk nursery non reactive to phage typing but plasmid profiling was helpful. R-plasmid analysis in these circumstances was useful, and for emerging pathogens such as Citrobacter, Enterobacter, or S. faecalis is often the only way to establish the identical nature of isolates. In using plasmid profiles for typing purposes, it is important that plasmid acquisition and plasmid loss by bacteria be taken into account. The technique is best used for investigating outbreaks or clusters and may be less useful over prolonged time periods.

The survival advantage conferred by R-plasmids to organisms within hospitals has made spread of these strains a concern beyond individual hospitals. A large outbreak of nosocomial infections due to Serratia mar- cescens resistant to many antimicrobials involved multiple hospitals in one city. ${ }^{11}$ Staff were shared by these institutions and indirect contact spread on the hands of personnel was the presumed mode of transmission. The dissemination of strains (or their plasmids) between two Veterans Hospitals reported by Shlaes in this issue probably follows a different mode of transmission. ${ }^{12}$ The most likely explanation for the events observed is interhospital transfer of one or more patients with subsequent dissemination of resistance. This creates special problems and concerns for infection control. We can usually identify a transferred patient actively infected with a resistant pathogen and alert the hospital or facility receiving the patient. Unfortunately, many patients are without symptoms and enormous resources would be necessary to identify all patients who are colonized but not infected by resistant flora. Even more global spread of R-plasmids has been noted by $\mathrm{O}^{\prime} B$ rien, ${ }^{13}$ highlighting that the problem is not confined to one ICU or hospital, but is an international one.

From the studies published in this issue and elsewhere, it is clear that R-plasmids play a central role in the problem of antimicrobial resistant nosocomial pathogens. The dynamic nature of this spread is clear. Our description of the problem is becoming more complete. We hope that successful control will soon follow.

\section{REFERENCES}

1. Kado CI, Liw ST: Rapid procedure for detection and isolation of large and small plasmids. J Bacteriol 1981; 145:1365-1373.

2. Macrina FL, Wood PH, Jones KR: Simple method for demonstrating small plasmid deoxyribonucleic acid molecules in oral streptococci. Appl Environ Microbiol 1980; 39:1070-1073.

3. Rubens CE, Farrar WE, McGee ZA, et al: Evolution of a plasmid mediating resistance to multiple antimicrobial agents during a prolonged epidemic of nosocomial infections. J Infect Dis 1981; 143:170-181

4. Tompkins LS, Plorde JJ, Falkow S: Molecular analysis of R factors from multiresistant nosocomial isolates. J Infect Dis 1980; 141:625-636.

5. Shlaes DM, Currie-McCumber C, Eanes M, et al: Gentamicin-resistance plasmids in an intensive care unit. Infect Control 1986; 7:355-361.

6. Weinstein RA, Kabins SA: Strategies for prevention and control of multiple drug-resistant nosocomial infection. $A m$ J Med 1981; 70:449-454.

7. Archer GL, Vishmiavsky N, Stiver HG: Plasmid pattern analysis of Staphylococcus epidermidis isolates from patients with prosthetic valve endocarditis. Infect Immun 1982; 35:627-632.

8. Archer GL, Karchmer AW, Vishniavsky N, et al: Plasmid-pattern analysis for the differentiation of infecting from non-infecting Staphylococcus epidermidis.J Infect Dis 1984; 149:913-920.

9. John JF, McNeill WF: Characteristics of Serratia marcescens containing a plasmid coding for gentamicin resistance in nosocomial infections. $J$ Infect Dis $1981 ; 143: 810-817$.

10. MCGowan JE, Terry PM, Huang TSR, et al: Nosocomial infection with gentamicin-resistant Staphylococcus aureus: Plasmid analysis as an epidemiologic tool. J Infect Dis 1979; 140:864-872.

11. Schaberg DR, Alford RH, Anderson R, et al: An outbreak of nosocomial infection due to multiply resistant Serratia marcescens: Evidence of interhospital spread. J Infect Dis 1976; 134:181-188.

12. Shlaes DM, Currie-McCumber C: Dissemination of a plasmid determining multiple antibiotic resistance between two veterans administration medical centers. Infect Control 1986; 7:362-364.

13. O'Brien TF, Pla MDP, Mayer KH, et al: Intercontinental spread of a new antibiotic resistance gene on an epidemic plasmid. Science 1985; 230:1365-1373. 